\title{
Medical Students' Perception of Community-Based Education Research and Services (Cobers) In Mbarara University of Science and Technology.
}

\author{
Ritah Naalia,1,2 \\ a Faculty of Medicine Department of Nursing, Mbarara University of Science and Technology
}

Abstract

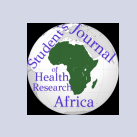

Background: ${ }^{a}$

The success of the Community Based Education Research and services (COBERS) in Mbarara University of Science and Technology plays a fundamental role in improving the community's health, education, and economics by sharing knowledge obtained from projects and increases the student's interest and participation in research while fulfilling the mission and vision of the university. The Student's perception of the Program contributes to compliance by Students to work in rural areas upon graduation, increases trust from communities, enhances the behavioral change and decreases costs to health departments, and facilitates development and implementation of more effective public health interventions. Most published studies reporting students' perceptions of COBERS are mainly from the developed world and only a few in Africa including Uganda. This report explored the overall Students Perceptions of COBERS at Mbarara University of Science and Technology.

Methodology:

A qualitative descriptive design was employed. The study involved thirty-three Medical students who were selected by purposive sampling. Data was collected using focused group discussions and analyzed manually to generate themes and subthemes.

Results:

Four themes emerged from eighteen categories describing Medical Students Perception of COBERS: An opportunity for interactions, the program is challenging, Attainment of skills, and an opportunity for interactions. These Qualitative findings reveal mixed feelings about COBERS.

\section{Conclusion:}

In conclusion, the four themes; An opportunity for interactions, the program is challenging, attainment of skills, an opportunity for translating theory to practice that emerged from eighteen categories were mostly expressions of perceptions of COBERS. These qualitative findings suggest that students' acceptance of COBERS as a requirement for Medical Schools is based on their perception of the expected outcome and the perceived benefits of their contribution to the community. These findings were from five focused group discussions where participants participated voluntarily in the study.

" Email: naaliritah2@gmail.com
Received: 29th/12/2020 Accepted:
5th/02/2021 Journal of Community
Health and Behavioural Sciences




\section{Background}

Community-based education research and services have been implemented and evaluated to improve the education of health professionals. This program was introduced in 2010 under the department of community health with an emphasis on using a multidisciplinary approach to understand and practically address health challenges in the community settings using the available resources (Najjuma et al., 2016). This has contributed to improved standards of living and quality of life particularly in communities of mid and South western Uganda in addition to helping the University in providing quality and relevant education both at the national and international level with emphasis on Science and Technology and its application to community development, as a way to meet this mission the university made it a requirement for all students in the FOM to participate in COBERS as partial fulfilment of their training for the award of the different bachelor's degrees (Mubuuke et al., 2015). The program is undertaken during the recess term of every academic year by students of MBChB4, MLS3, MLC, BNS3, BNC1, PHA2, PHS1, physiotherapy 3 , and visiting students from other universities. It's aimed at equipping students with skills that enable them to work together with communities to identify the challenges, find out their root causes, develop an action plan, gather resources, and involve the community in administering the interventions. Students are also required to participate in the provision of health care services in their respective health care facilities of detachment and as well taking part in primary health care activities during the 4weeksplacement (Ndaruhutse et al., 2016). It enhances students' attitude and willingness to provide services in rural areas with limited resources (Ndaruhutse et al., 2013). However little has been documented on students' perception of the purpose of the program to their profession, yet they are the end-users of the program. Hence, this study is aimed at assessing students' perception of COBERS at Mbarara University of science and technology.

Medical Schools are the primary institutions that train and graduate medical Doctors, Nurses, Pharmacists and other Health Professionals' hence contribute to an optimal workforce in the health sector (Chen et al., 2012). As healthcare becomes more specialized and fragmented, medical services are not being well-coordinated and medical expenditures continue to rise hence becoming a financial strain to the community while on the other hand there are regions where access to medical care is lacking (Yoo et al., 2018). The government of Uganda has implemented interventions such as salary supplements, recruiting medical students from rural areas, improving infrastructure and social amenities in rural areas; however, these have not yet succeeded in combating health workforce mal-distribution. Tovia et al., (2018) state that despite the various reforms brought in health care service delivery, there is always a gap between the community and health care providers hence need to reorient the medical students towards public health relevant community needs (Stephen., 2018).

Arja et al., (2018) assets that medical students struggle to advise patients in a local social-cultural context. It has been proven by Wilcox et al., (2015) that community-based Education can enhance the willingness of trainees to remain in their home countries after qualification and to practice in rural areas.

Medical schools worldwide are playing a role in addressing the shortage of rural health practitioners for example in New Zealand the Otago University Faculty of Medicine introduced a 7 Week rural undergraduate placement at the Dunedin School of Medicine in 2000 (Williamson et al., 2012). United Kingdom (UK) health policy has adopted an increasing community and primary care focus over recent years (Baglin et al., 2010). Similarly, several health professional training institutes in subSaharan Africa including in Uganda have adopted community-based education and services as an innovative approach that is likely to produce health workers who are equipped and willing to work in these rural areas (Kaye et al., 2010). Hence, the COBERS program was introduced as a compulsory curriculum component for five Medical Universities in Uganda that is Makerere University College of Health Sciences, Mbarara University of Science and Technology, Kampala International University, and Busitema University under the Medical Education for Equitable Services for All Ugandans Consortium (MESAU) with the major goals to sensitize and acclimatize students to working in underserved communities and enable them to acquire appropriate attitudes towards working in these areas (Kizito, 2017). 
According to Mubuuke et al., (2015), During COBERS, students learn from the community setting focusing on population groups and their everyday problems and the amount of time spent in the community and organizational settings may vary for example training may take place at a general practice, family planning clinic, community health center, or a rural hospital while empowering the local communities and at the same time learning from these people (Mubuuke et al., 2015). According to Kizito et al., (2017), The main components of COBERS are community health, community diagnosis, demography, communication skills, epidemiology, primary health care, biostatistics, health education and promotion, immunization, nutrition assessment, and community engagement (Wakida et al., 2015). The leadership and community placement (LCP)is preceded by 1-week classroom-based sessions at the university that employ interactive student-based learning Methodologies, using group discussions and assignments, role- plays, case studies, and to a lesser extent, lectures. The themes/ topics covered include scanning, focusing, planning, Aligning, mobilizing, and inspiring thus students are equipped with the knowledge and skills that enabled them to conduct their activities effectively while in the community (Najjuma et al., 2016). During this period, students are constantly supervised to ensure that the intended objectives are achieved (Mubuuke et al., 2015). The evaluation process comprises reports submitted and oral presentations done by students summarizing their activities (Kizito et al., 2017). The program enables medical students to understand the social needs and social factors influencing health and illness outside-classroom teaching and facilitates involvement in community services with the population who lacks health literacy thus increasing students' confidence (Milford et al., 2016). The course is geared towards instilling leadership knowledge and skills and Primary Health Care management essential for confronting the Health challenges of the 21stCentury (Ndaruhutse et al., 2013). It's indeed an integral and vital part of medical teaching which orients students to public health issues of relevance (Bhattacharya et al., 2018). Thus, its success and sustainability depend on its administration, coordination, perception, and values attached to it by its clients. For example, the students, site supervisors, Alumni, District staff, and communities where COBERS activities are located and occur (Mwanika et al., 2011).

Community-based education research and service is a university platform for enabling progressive transformative leadership and research related to medical education in Uganda. (Najjuma et al., 2016). Early exposure to the community in medical programs and involvement in the rural community may motivate medical students to practice in rural areas (Budhathoki et al., 2017). Furthermore, strengthening the linkages between medical students and the communities they serve can help address pressing health issues such as inadequate access to healthcare, lack of health insurance, and health disparities in our societies (Goldstein et al., 2011). In 2010, MUST introduced the COBERS program where a group of students in various medical fields is sent to various hard to reach areas with limited resources to produce health professionals with the right attitudes, skills, and commitment to work in rural places in Uganda where $80 \%$ of the population lives. Since then, the university has been sending students annually to such areas.

In 2012 the faculty of Medicine at MUST carried out site selection using the Medical Education for Equitable Services to All Ugandans (MESAU) consortium criteria for COBERS sites and identified 52 sites that met the criteria, of these currently only 34 are used for students' placement in southwestern Uganda (Ndaruhutse et al., 2013). According to Kruger et al., (2013), perception can be described as the information processing of cognitively received stimuli occurring about the world one lives in, it affects our thinking, decision making and defines what we regard as most important. However, no study has been conducted to explore medical student's perception of community-based education in Uganda and Mbarara University of Science and Technology.

During my informal interaction with medical and nursing students at MUST, there were mixed feelings regarding COBERS. This may inhibit students' productivity and academic achievement thus this study seeks to explore students' perception towards COBERS at MUST.

\section{METHODOLOGY \\ Study area}

The study was conducted at Mbarara University of Science and Technology in Mbarara town on the 
Mbarara -Kabale Highway approximately 266 kilometers southwest of Kampala, Uganda's capital and largest city. The area offers medical undergraduate courses such as Bachelor of Medicine and Bachelor of Surgery, Bachelor of Science in Nursing, Bachelor of Pharmacy, Bachelor of Science in Physiotherapy, Bachelor of Medical laboratory science, Bachelor of Science in pharmaceutical sciences which are key participants in the Community Based program. MUST was chosen as a study area because it annually participates in the COBERS program by sending its students in FOM to various hard to reach areas in south western Uganda.

\section{Study design}

The study employed a qualitative phenomenological design. The study design was preferred because it explained and described the phenomenon and allowed for in-depth exploration of issues of interest (Burns and Grove, 2003) which in this case was medical students' perception of COBERS in MUST.

\section{Study population}

The study participants were medical students pursuing Bachelors in pharmaceutical sciences in the second year, pharmacy in 3rd year, nursing in 4th year, physiotherapy in 4th year, nursing in 4th year, Medical laboratory sciences in 4th year and medicine and surgery in 5th year and living in the study area. They are 300 students.

\section{Data collection method.}

Data was collected using focused group discussions. The discussions and interviews were chosen because they enhance the credibility of the study since it seeks to explore the participants' perceptions of COBERS. The interview guide is formulated to obtain data about the study objective.

\section{Data collection tools.}

\section{The data was collected using:}

An interview guide was used to engage participants with the interview.

An audio recorder was used to help the researcher to concentrate on the conversation.

These tools were regarded as appropriate tools that could be used for this study.

\section{Data collection procedure.}

Data was collected using a focused group interview guide. The researcher asked relevant questions and an audio recorder was used to record the students' responses. Each focused group discussion took approximately 20-40 minutes. All members participate actively and informed consent was obtained from participants before the interview. At the end of the discussion, participants were thanked, encouraged to ask questions which were answered to the participant's satisfaction.

\section{Inclusion criteria}

The study included 5 groups of medical students each group consisting of one student from each course that is those in 2ndpharmaceutical sciences,3rdpharmacy students, 4th nursing students,4thmedical laboratory students, and 5th-year medicine and surgery students who had undergone COBERS training.

\section{Exclusion criteria}

\section{The study excluded;}

Those that the researcher knows personally to avoid bias

\section{Sampling procedure}

Purposive sampling methods were used in this study targeting all medical students who have been to the community for COBERS in the last two years. It's assumed that the students are knowledgeable enough and have taken part in the program hence they will be able to give relevant and adequate information concerning their perspectives. The researcher identified the total population that met the inclusion criteria which was 300 , determined the appropriate sample size.

\section{Sample size determination}

There were5 focused group discussions where each discipline had at least 1 member and the group consisted of 6-12 participants. According to Polit and Beck (2012), a sample size of 6-12 participants is sufficient as the emphasis is put on the richness of the data collected and not the number of study participants. Hence the sample size of the study was determined by redundancy whereby no new information is extracted from participants (Polit and Beck,2012).

\section{Data Analysis.}

This was done using the thematic content analysis basing on emerging themes, it was done in three phases, pre-analysis, material exploration, and result treatment (McCuster et al.,2011). In preanalysis, the researcher transcribed all the interviews immediately after completing them. The unit analysis was focused on groups. Thereafter the thematic analysis of data was done using the highlighting approach described by Van-Manen (1997). The researcher identified and organized significant 
statements and commonalities into themes representing important aspects of the students 'perceptions' immediately after the interview.

Emergent themes were documented. The following seven steps were followed during data analysis:

The researcher read and re-read the participant's descriptions of the phenomenon to acquire cognition for their experiences and make sense of their account.

The researcher Extracted significant statements that pertained directly to the phenomenon.

The researcher Formulated meanings for these significant statements. The formulations must discover and illuminate meanings hidden in the various contexts of the investigated phenomenon.

The researcher Categorized the formulated meanings into clusters of themes that were common to all participants. Referring these clusters to the original transcriptions of validation and confirming consistency between the investigators emerging conclusions and the participants' original stories; not going into the temptation to ignore data which did not fit or pre-maturely generating a theory which conceptually eliminated the discordance in findings.

The researcher Integrated the findings into an exhaustive description of the phenomenon being studied. The researcher Employed a self-imposed discipline and structure to bridge the gaps between data collection, intuition, and description of concepts. The description included coding segments of text for topics, comparing topics for consistent themes, and bridging themes for their conceptual meanings. Based on this description a prototype of a theoretical model about the phenomenon under investigation was formulated.

The researcher Validated the findings by returning to some participants.

The researcher Incorporated any changes offered by participants into the description of the essence of the phenomenon.

\section{Rigors of research}

Rigors are related to establishing the trustworthiness of the data and the study. In qualitative research, an attempt is made to approach the understanding of the participants' outlook through interview thus the term trustworthy. Trustworthy which was first proposed by Guba and Lincoln in the middle 1980s presented four (4) parameters that include Credibility, Transferability, Dependability, and Conformability (Ghafouri, 2016).

\section{Credibility.}

According to Ghafouri et al., (2016), It is seen as the most important aspect in establishing trustworthiness. It was achieved by using a purposive sampling method.

Questions were adequately explained to the respondents during the discussion for purposes of understanding to avoid vague answers. It was also ensured by strictly following the inclusion and exclusion criteria stipulated above, pretesting the data collection tool, and prolonged engagement by allowing ample time for the participants to explain their perceptions during the interview. A pilot study refers to the mini-study done before the main study to ensure the comprehensive and accuracy of the interview guide. It was used to pretest the data collection tool. It was conducted at Bishop Stuart University in Mbarara were only 6-10 Nursing students participated in the study. Any gaps that were identified in the data collection tool were corrected based on the feedback from the pilot study. This helped the researcher gain more knowledge and skills in data collection.

\section{Transferability.}

According to Lincoln et al., (1985), transferability refers to the degree to which the results of the study can be generalized or transferred to other contexts or settings. This was facilitated through the thick description of the setting and participants hence this encouraged the researcher to provide a detailed portrait of the setting in which the research was to be conducted. The intention was to give readers enough information for them to judge the applicability of the study findings to other settings. It was attained by allowing each participant to explain his or her independent perceptions of COBERS until no new information was aired out.

\section{Dependability.}

According to Polit et al., (2006), Dependability refers to the stability of data over time and conditions. This was achieved through carefully listening to the recorded responses and going back to the study participants to confirm their perceptions of COBERS in Mbarara university of science and technology.

\section{Conformability.}

According to Polit et al., (2006), conformability refers to the neutrality of the data or analysis and its interpretation. This was achieved by including narrative quotes in my final study findings.

\section{Data management}


The researcher passed through the interview guide used during the focused group discussion since it elicits a verbal response from participants. The recordings were transcribed with no names or identifying information. The transcribed text will then be cleaned and then data will be sorted out according to the variables. The interview guide was kept safe to avoid losses and mishandling as they will be used for reference purposes.

\section{Ethical consideration}

Ethical approval was sought from the MUST Faculty Research Committee (FRC). Request for permission was obtained from the Dean of the Faculty of Medicine. Informed consent was obtained from individuals that were willing to participate in the study. Confidentiality was ensured during the discussions as no names will be used; only codes and the information generated were kept under key and lock only accessible by the researcher.

\section{Dissemination of results.}

The results from my study were submitted to the faculty of medicine specifically to the Department of Nursing at MUST. A copy was submitted to the University Nursing Library. study findings were published.

\section{Limitations}

Being a qualitative study, a few participants were used and therefore the findings cannot be generalized but only transferable.

The findings can be affected by individual competencies since human beings were the instruments for data collection.

There was limited information found online about medical student's perception of COBERS in Uganda and particularly local data.

\section{RESULTS}

\section{Demographic characteristics focused group dis-} cussions

FGD1 - 7 participants from different courses that are 4th-year bachelors of science in nursing, bachelors of science in physiotherapy 4th year, bachelor of pharmacy 4th year, bachelor of medicine and surgery 5th year, bachelor of medical laboratory sciences 4 th year, bachelor of science in nursing completion 2nd year, bachelor of pharmaceutical sciences 3 rd year where 3 were females and 4 were males.
FGD2 - 7 participants from different courses that are 4th-year bachelors of science in nursing, bachelors of science in physiotherapy 4th year, bachelor of pharmacy 4th year, bachelor of medicine and surgery 5th year, bachelor of medical laboratory sciences 4 th year, bachelor of science in nursing completion 2 nd year, bachelor of pharmaceutical sciences $3 r d$ year where 3 were females and 4 were males.

FGD3 - 6 participants from different courses that are 4th-year bachelors of science in nursing, bachelors of science in physiotherapy 4th year, bachelor of pharmacy 4th year, bachelor of medicine and surgery 5 th year, bachelor of medical laboratory sciences 4th year, bachelor of science in nursing completion 2 nd year. where all were males.

FGD4 - 6 participants from different courses that are 4th-year bachelors of science in nursing, bachelors of science in physiotherapy 4th year, bachelor of medicine and surgery 5th year, bachelor of medical laboratory sciences 4 th year, bachelor of science in nursing completion 2nd year, bachelor of pharmaceutical sciences 3 rd year where 3 were females and 3 were males.

FGD5 - 7 participants from different courses that are 4th-year bachelors of science in nursing, bachelors of science in physiotherapy 4th year, bachelor of pharmacy 4th year, bachelor of medicine and surgery 5 th year, bachelor of medical laboratory sciences 4th year, bachelor of science in nursing completion 2nd year, bachelor of pharmaceutical sciences 3 rd year where 2 were females and 5 were males.

Four themes emerged as perceptions of medical students towards community-based education and Research at Mbarara University, these include;

\section{Theme one: An opportunity for interactions}

This theme emerged from several subthemes emphasizing how they can interact with fellow students from different disciplines, with the community, and the health workers at the health facilities they are placed.

Participants perceptions indicated that the program enables them to socialize, work with each other, with the community, make new friends, associate directly with the community and make connections as stated below;

\section{Interdisciplinary;}

Participants perceptions indicated that COBERS has enabled them to connect with students from other disciplines to solve complex challenges while 


\begin{tabular}{ll}
\hline THEMES & SUBTHEMES \\
$\begin{array}{l}\text { 1. An opportunity for } \\
\text { interactions }\end{array}$ & $\bullet$ Inter disciplinary $\bullet$ Students-health workers $\bullet$ Students-community \\
$\begin{array}{l}\text { 2. The program is } \\
\text { challenging }\end{array}$ & $\begin{array}{l}\text { - Poor student's welfare } \bullet \text { Inadequate planning and supervision } \bullet \text { Limited time in } \\
\text { community } \bullet \text { Difficult decision making as a group. } \bullet \text { Language barrier } \bullet \text { Heavy } \\
\text { work load }\end{array}$ \\
$\begin{array}{ll}\text { 3. Attainment of skills } & \text { - Social skills } \bullet \text { Basic skills } \bullet \text { Communication skills } \bullet \text { Leadership skills } \bullet \text { Career skills } \\
\text { 4. An opportunity for } & \text { - An opportunity to Identify health related challenges in the community } \bullet \\
\text { translating theory to } & \text { opportunity to bridge the theory practice gap } \bullet \text { primary prevention } \bullet \text { Role of } \\
\text { practice } & \text { different disciplines }\end{array}$ \\
\hline
\end{tabular}

they are staying in the same household and sharing needs which are very rare at the campus as noted in their excerpts below;

You get to interact with different people because you find that at the station you have one student or two from each discipline you have a pharmacy, PHS, MLS, MLC which at the end of the day you will still have the same like maybe in a hospital setting or other settings........................ (P3P1P4FGD1, P3FGD5)

It allows that interactions between different professionals from different disciplines to work together not only in the hospital setting but also in the community................p1FGD4P3P7P5FGD1, P7P2FGD2,

\section{Students-health workers}

Participants perception indicated that they were able to share their views and ideas with the health workers and various stakeholders that they came across during the placement and they were able to make new friends, connections and most of them are still in touch with the health workers at those COBERS placement sites as mentioned below;

The doctor in charge told us that for them they make so much money even more than the doctors in a referral hospital and I got new friends like the DHO and if any opportunity can easily connect ............................. P3FGD4

We experienced how the health center operates we got to know the different cadres in the health centers we got to know the services they do which were very good in terms of our work relationship........... p7FGD5

What we learned was to work with different people and random people and we learned how to settle in a new workplace and you know work environment and new people and work with them................p2FGD4

\section{Students-community}

Participants' perceptions on COBERS regarding community indicated that the program enabled them to get an in-depth insight on what happens in other parts of the country far away from cities since they were directly involved with the people in the community, sharing the same environment and resources while engaging them to find out how they perceive their health and solve some of the challenges unknown to the health workers in the hospital setting as noted below;

Going down to the community to that person who receives that service and then you engage with them and you know how they perceive things................ p4FGD5

It helped us understand that even passed us giving the medicine and the diagnosis we need to involve the community more to have the best outcome...............p6FGD5

Learned how I can get to involve the community in solving the problems that they have and You know how they perceive things and how they get around and solve the problem at hand............... p4FGD2FGD5, p3FG3

\section{Theme two: The program is challenging}

Participants' perception of the programming being challenging emanated from the subthemes of poor student's welfare in terms of housing, electricity, internet, and security, inadequate supervision at both the facility and community, limited time in the community, difficult decision making as a group, language barrier, heavy workload.

\section{Poor student's welfare;}

Participants' perception towards their welfare while in the community noted that the participants did not feel comfortable and most of them were disappointed with the kind of services provided such as the kind of housing they got for them, elec- 
tricity, climate conditions, nutrition, health, security because what they were told they would find at the placement sites was not there as indicated below;

It created a lot of threats to very many students for example during that time there was an Ebola outbreak, stuff was stolen, some of us fell sick, we were bitten by fleas, the room was too cold P7FGD2, P1P2FGD1, P1FGD2, P6FGD4

There was no food we ate posh and beans everyday restaurants around didn't have good food. . P6FGD2, P6FGD3

.... The moment we reached there our lines went off with heavy rain polls could fall and Umeme would take like a week to respond. P1FGD2

\section{Inadequate supervision and planning;}

Participants' perceptions towards supervision and planning indicated that they lacked someone to oversee the activities carried out at both the facility and in the community, some noted that they were not helped by the supervisors assigned to them since these supervisors did not give much attention and time. some were stranded at the placement sites with no one to receive them so they kept wondering if the university does ground research before sending students to these placement sites as indicated below;

She came like twice and every time she could come she would say we have done nothing so we had to go back and start afresh........... P7FGD1, P6FGD3, P3FGD1

We were the pioneers at the site the person who we were told was to receive us on arrival we were told she had gone for leave a month ago while the others in charges were not informed..............P1FGD1, P5FGD3, P3, P1FGD4, P6FGD3

......the way students go to the field and they can easily post data there is no one following up to know exactly what they are doing on actual ground........... P5, P1FGD4

\section{Limited time in the community;}

Participants perception of the time allocated to the program indicated that it was too little for them to accomplish all they had to do in the community hence this resulted in a lot of stress and anxiety as noted below;

............after identifying the challenge you are supposed to come up with a measurable result in 4weeks...... P4FGD3 ...........to come up with the problem and all things they require us to do we had to put in a lot......... P4, P2FGD4

\section{Difficult Decision making as a group;}

Participants' perception of COBERS indicated that they got a lot of difficulty in making decisions as a group since they all had different ideas and considered the magnitude of different identified challenges differently. This is depicted from responses of participants as noted below;

We were very many people like you want to do this then the other wants to do something different............P4FGD1, P6FGD3

We disagreed people had different ways of seeing things so everybody wanted to solve their own problem..... P4FGD2, P3FGD3

Some people were not around sometimes those people would get problems and we would disagree on some things. . P2FGD2, P3FGD2

\section{Language barrier;}

Participants described language barrier as a very huge obstacle as it affected the way they delivered the information to the community because they were unable to speak a common language as noted below;

.......... there we had only 2 people in my group who would speak Rutooro so that was a tag of war......P5FGD1

We had only one person who would speak Runyankole we could construct sentences when you don't even know the meaning but either way you need the information. . P7FGD, P1FGD3, P2FGD3

I was the only one who could speak Kinyarwanda so you find that everything is on you.........P3FGD2

\section{Heavy workload; '}

Participants perception indicated that they had a lot of things to do due to an increase in the daily turn-up of patients when they discovered that health workers from Mbarara had come to work at the facility and yet they also had to go to the community so this caused them a lot of stress and increased the risk of absenteeism at the facility due to fatigue as mentioned below;

......... I don't know how news spread to the whole village may be ba doctor be Mbarara baze (doctors from Mbarara have come) like people were very many I think we worked on people up to evening ...P4FGD2

........we started getting like abnormally high numbers of clients within that per day so it was very tiresome.............P4FGD3 


\section{Theme three: Attainment of skills}

This theme emerged from five categories which include: Social skills, Basic skills, Communication skills, Leadership skills, Career skills.

\section{Social skills.}

The participants expressed acquisition of skills that enabled them to communicate and interact with others both verbally and non-verbally without necessarily hurting each other's feelings as indicated below;

It changes the way we conduct ourselves.......... P7FGD1

We kinder started learning the personalities of people and how we can work with them without compromising our principles...... P6FGD1

It's a wonderful idea for medical students because among the several things that we had are social skills...........P2FGD4

\section{Basic skills}

The participants indicated in the responses below that they were able to gain some life-changing skills that enabled them to actively participate in working with the community.

...... The practical aspect I had never tried to inject anybody which I learned....... P6FGD1, P1FGD2

......... Making tippy taps I had never seen and digging a hole using a spear...... P1 FGD2

Life wasn't the best but you get to know that you have to adjust according to the situation............... P1FGD4

\section{Communication skills.}

Percipients' acknowledged that they were able to communicate effectively and pass on information to other people, to their superiors, colleagues, community gatherings, and staff as indicated below;

You get to learn other skills like talking to people and use other forms of communication............ P1FGD2

......we would sensitize community members.............. P2FGD3

Also, learned how to pass out a communication to the community members I had not done before. . P4FGD4

\section{Leadership skills}

Participants perceptions towards the leadership training they underwent before heading for placement indicates that it was really useful as it aided them to think, plan, communicate, innovate and manage people as noted below;

I realized that the way we were supposed to lead ourselves as students was amazing when we reached the community we had to apply the same skills to mobilize the communities..........P2FGD1

leadership training, they gave us at campus it helped us a lot. . P4FGD3

By the time we went to the community we were already conversant with what will be done........... P1FGD3, P3FGD3

\section{Career skills}

Participants' perception of the COBERS program indicated that it helped them to increase their knowledge, skills, and experience which is vital in determining the students' success in decisionmaking, influencing others, and getting the job done as well. This depicted by the participants' responses below;

It high lightened the need for us to put in more efforts into our studies..........P6FDG1

It helps us go out in the field to learn a few things that we will apply in our career......... P2FGD2

Theme Four: An opportunity for translating theory to practice

This theme emerged from four categories namely: An opportunity to Identify health-related challenges in the community, an opportunity to bridge the theory and practice gap, primary prevention, Role of different disciplines.

An opportunity to Identify health-related challenges in the community.

Participants' perceived the program as being beneficial to them since they were exposed to the environment in the community hence they experienced the same kind of lifestyle similar to that of people living in that community thus they were able to see where the actual challenges come from as noted below;

When we reached there actually we saw the source of problems............P2, P7FGD1, P3FGD3, P4FGD3

It gave us an appreciation of the prevalence of problems............P6FGD1, P2FGD4

When you are in the community and you see what affects them it helps you come up with better ideas.........P7FGD2, P3FGD4

\section{Opportunity to bridge the theory and prac- tice gap}

Participants expressed their views concerning what they are taught at the university which is required in the ideal setting where everything concerning resources is available for use which is way too different from what they found in the community where they had to improvise since they were 
working under limited resources as mentioned by the participants below;

......We are taught what they want us to do but when you reach community you find that you have limitations...... P6FGD1

...... there are some misconceptions that the community has about very many approaches......P6FDG1

...........things that appear obvious are not obvious to the people in the community........... P5FGD3

\section{Primary prevention}

participants' perceptions indicated that primary prevention whereby they aimed at different measures that would prevent the disease from occurring through health education, immunization was very important because they would decrease the heavy workload at the health facilities as mentioned below;

...... preventing the disease from occurring than actually waiting for it to occur is the best.........P1P4FGD1, P1FGD3

.... It focuses more on the primary health care gap rather which we don't see when at the hospital......P5FGD1

It shows that it's very important to prevent than to go ahead to cure................P5FGD2

\section{Role of different disciplines}

Through COBERS the participants noted that they were able to see what happens in the different disciplines and how each discipline works to impact the health sector as noted below;

Everyone has something to contribute because of the ego tendencies sometimes we tend to forget....................P6FGD1

We were able to work together and appreciate the role of every discipline in the management of disease...........P7FGD2, P1FGD2, P4FGD2

.........me am a pharmaceutical scientist we are so much in the lab and stuff like that so we never get to know what happens on the other side but they were able to help us understand the dynamics that happen on the other side............ P4FGD2

\section{DISCUSSION}

Our study found students had positive perceptions about the COBERS program for this has effects on their performance and practice since it outlines their responsibility and general mentality towards their profession. The study revealed that students' exposure to the COBERS program is crucial. COBERS exposes them to the rural setting since most of them have been brought up in town hence they get to experience a different kind of setting hence changing their view on issues affecting the community. This finding is in agreement with Williamson et al., (2012) who found out that there is a strong effect of rural origin on doctors choosing to work in rural areas.

The study demonstrated that putting students from different courses together and placing them at different sites helped them gain several basic skills, competencies in various activities, socialization and learn a lot from colleagues in other disciplines since is the same kind of environment they will be exposed to after school in their work areas. This finding is in line with that of Liu et al., (2019) who emphasize that nurses learn their core competencies from their role relationships with other medical practitioners, socialization, acculturation to nursing practice, and acquisition of knowledge embedded in practice.

Students emphasized that the COBERS Program enabled them to experience the way health centers operate, how they work under limited resources, what different cadres do offer, how stakeholders manage to provide services to the community, and the different challenges they get when providing these services hence giving them a clue on what is going on the actual ground in the country. This finding is in line with Mullan et al., (2011) who reported that structured community exposure and community-based Education provide students with experiences of working with underserved populations, this improves the students' preparation to deal with nation health problems.

Our study found out that the COBERS program benefits all those involved that is the students, the health workers at the placement sites the community, and the institution which included students gaining expertise in skills, knowledge, and technical know-how, health workers going for leave and having enough rest due to additional manpower provided to the health facility by the students, the community members being able to get health services offered to them in time and gaining knowledge on issues affecting their communities. This is similar to Diab et al., (2013) who argued that COBERS is an awin-win program as it provides both the training institution and the service site with additional resources and the benefit to students is 
well documented in the literature, the students also revealed improved practical knowledge, skills and a more positive attitude towards their patients and colleagues further enabling them to understand the relevance of their training.

Participants expressed that although the program is good there are a lot of challenges that they encounter during COBERS which need to be improved. These challenges include poor housing, lack of enough funding, lack of motivation for stakeholders in form of incentives from the university, poor road, insecurity, poor network, and internet services. This finding is in line with Amalba et al., (2019) who suggested that despite the acknowledgment that there are many challenges such as lack of social amenities, poor roads, and transportation network, poor accommodation both students and community members expressed high satisfaction. Also, some participants were not willing to go back to work in these areas due to the high expenses encountered during the COBERS Placement. This finding is in line with Amalba et al., (2016) who expressed that socio-economic conditions negatively impact the willingness of healthcare professionals to work in rural areas in developing countries.

\section{Conclusions}

In conclusion, the four themes; An opportunity for interactions, the program is challenging, attainment of skills, an opportunity for translating theory to practice that emerged from eighteen categories were mostly expressions of perceptions of COBERS. These qualitative findings suggest that students' acceptance of COBERS as a requirement for Medical Schools is based on their perception of the expected outcome and the perceived benefits of their contribution to the community. These findings were from five focused group discussions where participants participated voluntarily in the study.

\section{Recommendations}

The results from the focused group discussions held with students regarding their perceptions about COBERS revealed missed reactions and these include;

The program is crucial to students as it benefits them a lot which is paramount for their career advancement therefore the committee needs to clearly outline the clear objectives of the program to students and improve on supervision of students at both the facility and community so that they can add more value to the community.

The COBERS team should carry out ground research about the placement sites by individually visiting these areas before sending students and also improve students' welfare through funding students according to the situation at the placement sites so that the students undertaking the program are comfortable and psychologically prepared before placement in an attempt to change the negative perceptions.

There should be an increase in the period students spend in the COBERS program in an attempt to alleviate stress and anxiety.

The programmers should review the student's reports and work on those challenges that students outlined in their reports so that they can enhance the training.

The students opted for any other form of assessment since they believe the current one favors cram work and forgery of results and to them, it seems not to favor the community because the programs are not followed up by the university.

The university should consider providing motivation inform of incentives to the various stakeholders to reduce the financial burden encountered by the group in motivating the stakeholders who always expect something from the university for which in actual sense the

\section{Nursing implications}

The results of this study contribute to the understanding of students' perceptions of COBERS. The study lends evidence to our program about how students need to undergo COBERS training to enhance a better understanding of the community.

In practice, nurses form avital part of the interdisciplinary team in the health care system. They provide holistic care in integration with the intended patient care hence suiting them in these groups helps them build confidence and develop other skills that will aid them to advocate for better health care service delivery.

Therefore, there is a need to educate students on the relevance of the aims and objectives of the program to achieve the goal for which the program was started.

\section{Areas for further research}

Similar studies should be conducted in other Universities in the country and the results compared will help strengthen the role of COBERS. 
Since this is qualitative research, quantitative research should be done on accessing Students' satisfaction of COBERS.

Another study on COBERS should involve the community members as participants.

\section{Acknowledgment}

I give honor to the almighty God for giving me the strength, grace, wisdom, patience, and understanding that made me able to accomplish this task.

I send my sincere appreciation to the Must department of Nursing and my Supervisor MR. Niyonzima Vallence for guidance, encouragement, support, and educational advice throughout the study.

I also send my sincere gratitude to the MUST Dean of students who granted me an opportunity to collect data from students in the faculty of Medicine.

I send my gratitude to my parents who have greatly contributed emotionally and financially to the success of my research

I also send my gratitude to all students in the Faculty of medicine for sparing their time and voluntarily participating in my study, I pray the almighty God rewards them abundantly.

\section{List of Abbreviations}

BNC Bachelor of Nursing Science Completion Program

BNS Bachelor of Nursing Science

COBERS Community Based Education Research and Services

FOM Faculty of Medicine

FRC Faculty Research Committee

LCP Leadership and community placement

MBCHB Bachelor of Medicine and Bachelor of

Surgery

MESAU Medical Education for Equitable Services for All Ugandans Consortium

MLC Medical Laboratory Sciences Completion

MLS Medical Laboratory Sciences

MUST Mbarara University of Science and

Technology

PHA pharmacy

PHS Pharmaceutical Sciences

UK United Kingdom

\section{Definition of Terms}

Bachelor of Nursing Science Completion Program (BNC):
These are nursing students enrolled from diploma level to pursue a bachelor's degree for which the program lasts for 2 years.

\section{Bachelors of Nursing Science (BNS):}

These are nursing students who are enrolled directly from high school to university.

\section{Community-Based Education Research and} Services:

it's a program offered to all medical students by the University in which students in various medical fields are sent to various hard to reach areas with limited resources to produce graduates who can face challenges in the health sector.

\section{Faculty of Medicine:}

It's a faculty that comprises and is concerned with medical-related courses at Mbarara University of Science and Technology. It comprises of various departments which offer courses such as Nursing, Pharmacy, Medical Laboratory Sciences, and physiotherapists, Medicine and Surgery, Pharmaceutical Sciences.

\section{Medical students:}

This is a term used to describe all students pursuing Medical Courses in the Faculty of Medicine such as those pursuing $\mathrm{MBCHB}, \mathrm{BNS}, \mathrm{BNC}, \mathrm{PHA}$, PHS, MLS, MLC, and Physiotherapy

Nursing students: Students pursuing BNS and BNC courses.

Perceptions are the organization, identification, and interpretation of sensory information to represent and understand the presented information or the environment. It also refers to how something is regarded, understood, or interpreted.

\section{References:}

1). Amalba, A., Abantanga, F., Scherpbier, A. J. J. A., Mook, \& Walther, N.K.A.V. (2019) "The role of Community-Based Education and Services (COBES) in Undergraduate Medical Education in Reducing the Mal-Distribution of Medical Doctors in Rural Areas in Africa: A Systematic Review". Health Professions Education.

https://doi.org/10.1016/j.hpe.2019.09.003

2). Amalba, A., Abantanga, F., Scherpbier, A. J. J. A., Mook, \& Walther, N.K.A.V. (2019) "Trainees' preferences regarding choice of place of work after completing medical training in traditional or problem-based learning/community-based education and service curricula: a study in Ghanaian medical schools.19(3) 
3). Amalba, A., Karel, W.N., Mook, A.V., Mogre, V., \& Scherpbier, J.J.A. (2016) "The effect of Community Based Education and Service(COBES) on medical graduates' choice of specialty and willingness to work in rural communities in Ghana" BMC Medical Education 16:79. https://doi.org/10.1186/s12909-0 16-0602-8 PMid:26931412 PMCid:PMC4774102

4). Arja, S.B., Arja, S.B., Chunchu, V, A., Narendra, S., \& Datla, A, B. (2018) "Students perception on community based education at Avalon University School of Medicine during the first two years of the program".

https://doi.org/10.15694/mep.2018.0000190.1

5). Beglin, M.R \& Rugg, s. (2010) "Student nurses' experiences of community-based practice placement learning: a qualitative exploration". Nurse Educ Pract 10(3): 144-52.Epub2009 Jun 30. PMid:19570716

https://doi.org/10.1016/j.nepr.2009.05.008

6). Chen, Candiac., Buch, Eric., Olaopa, \& O.O.E. (2012) "A survey of Sub-Saharan African medical schools" Human Resources for Health 10(4).

https://doi.org/10.1186/1478-4491-10-4

PMid:22364206 PMCid:PMC3311571

7). Diab, P., \& Flack, P. (2013) "Benefits of community based education to the community in south African health science facilities" Afr J Prim Health Care Fam Med.5(1) Art.474,6 pages. https://doi.org /10.4102/phcfm.v5i1.474 PMCid:PMC4709640

8). Ghafouri, R., \& Ofoghi, S. (2016). "Trustworthy and rigors in qualitative research". International journal of advanced research.

9). Goldstein, A. O., \& Sobel, R. (2011) "Community engagement in US and Canadian medical schools". Adv Med Educ Pract. 2:43-49.

https://doi.org/10.2147/AMEP.S16823

PMid:23745075 PMCid:PMC3661243

10). Kaye, D.K., Muhwezi, W.W., Kasozi, A.N., Kijjambu, S., Mbalinda, N.S., Nabirye, R.C., Okullo, I., Mwanika, A., Oria, H., Atuyambe, L., Groves, S., \& Burnham, G. (2011) "Lessons learnt from comprehensive evaluation of community-based education in Uganda: a proposal for ideal model community based education for health professional training institutions. BMC Med Educ 11,7 https://doi.org/10. 1186/1472-6920-11-7

\section{PMid:21362181 PMCid:PMC3056836}

11). Kaye, D.K., Mwanika, A., \& Sewankambo, N. (2010) "Influence of the training experience of Makerere University Medical and Nursing graduates on willingness and competence to work in rural health facilities". Rural Remote Health 10(1):1372

12). Kelly, Len., Walters, Lucie. Rosenthal, \& David. (2014) "Community-based medical education: is success a result of meaningful personal learning experience?" General Article 27(1). https://doi.org/10.4103/1357-6283.134311 PMid:24934943

13). Kizito, S., Baingana, R., Kintu, M., Akera, P., \& Sewankambo, K.N. (2017) "Influence of community based education on undergraduate health professions students' decision to work in underserved areas in Uganda" BMC Research Notes 10:726.

https://doi.org/10.1186/s13104-017-3064-0 PMid:29221498 PMCid:PMC5723038

14). Liu, Y.P., Jensen, D., Chan, Cho-yu, C., Wei, C., Chang, Y., Wu, C., \& Chiu, C. (2019) "Development of a nursing-specific Mini-CEX and evaluation of the core competencies of new nurses in postgraduate Year training programs in Taiwan." BMC Medical Education 19:270. https://doi.org/10.1186/s12909019-1705-9 PMid:31319845 PMCid:PMC6639917

15). McCusker, J., Cole, M. G., Voyer, P. J., Monette, J., Champoux, N., \& Ciampi, A., (2011), "Use of nurseobserved symptoms of delirium in long-term care: effects on prevalence and outcomes of delirium", Intpsychogeriatr,23(4),602-608.

https://doi.org/10.1017/S1041610210001900

PMid:20880428

16). McCusker, J., Cole, M. G., Voyer, P. J., Monette, J., Champoux, N.,\& Ciampi, A., (2011), "Use of nurseobserved symptoms of delirium in long-term care: effects on prevalence and outcomes of delirium", Intpsychogeriatr,23(4),602-608.

https://doi.org/10.1017/S1041610210001900 PMid:20880428

17). Mubuuke, A.G., Oria, H., Dhabangi, A., Kiguli, S., \& Sewankambo N.K. (2015) "An exploration of undergraduate medical students' satisfaction with faculty support supervision during community placements in Uganda." Rural and Remote health 15(4):3591.

18). Mullan, F., Frehywot, S., Omaswa, F., Bunch, E., Chen, C., Greysen, S.R., Wassermann, T., Abubakr, D.E.E., Awases, M., \& Boelen, C. (2011) "Medical schools in sub-Saharan Africa" The Lancet. 377(9771): 1113-1121.doi 10.1016/S01406736(10)61961-7.

https://doi.org/10.1016/S0140-6736(10)61961-7

19). Najjuma, J.N., Ruzaaza, G., Groves, S., Mailing, S., \& Mugyenyi, G. (2016) "multidisciplinary Lead- 
ership training for undergraduate health science students may improve Ugandan healthcare".

https://doi.org/10.7196/AJHPE.2016.v8i2.587

20).Ndaruhutse, G.R., Ntaro, M., Maling, S., Arubaku, W., Batwala, V., \& Mulogo, E. (2013) "Community Based Education Research and Service Training(COBERS)" handbook First Edition.

21). Polit, D., and Beck, C.T. (2012). "Nursing research: Generating and assessing evidence for Nursing Practice," Philadelphia, PA: Wolters Kluwer.

22). Polit, D.F., and Beck, C.T. (2006)." Essentials of Nursing research: methods, appraisal and utilization Denise F Polit Essentials of Nursing research: methods, appraisal and utilization." Nurse Researcher 1; 13(4):91-92. https://doi.org/10.7748/ nr.13.4.91.s11 PMid:27702222

23). Stephen T, Selvaraj K, Bazroy J, Antony V, Singh Z, \& Purty AJ. (2018). Impact of community based training on medical undergraduates skills upgradation regarding infant and young child feeding practices: A mixed method study. Indian J Community Fam Med;4:52-7

https://doi.org/10.4103/2395-2113.251350

24).Tovia, S., Kalaiselvi, S., Bazroy, J., Antony, V., Singh, Z., \& Purty, J.A. (2018) "Impact of community based training on medical undergraduates' skills upgradation regarding infant and young children feeding practices: Amixed method study". Original Article 4(1).

https://doi.org/10.4103/2395-2113.251350

25). VanManen, M., (1997). "Researching lived experience: human science for an action sensitive pedagogy," Althouse Press, Ontario, 2nd edition.

26). Wakida, E.K., Ruzaaza, G., Muggaga, k., Akera, p., Oria, H., \& Kiguli, S. (2015) "Healthprofession students teaching and learning expectations in Ugandan medical schools: pre-and postcommunity placement comparison."Adv. Med Educ Pract.6:641-56.

https://doi.org/10.2147/AMEP.S91624

PMid:26677345 PMCid:PMC4677597

27). Wakida, E.K., Ruzaaza, G., Muggaga, k., Akera, p., Oria, H., \& Kiguli, S. (2015) "Healthprofession students teaching and learning expectations in Ugandan medical schools: pre-and postcommunity placement comparison."Adv. Med Educ Pract.6:641-56.

https://doi.org/10.2147/AMEP.S91624

PMid:26677345 PMCid:PMC4677597

28). Wilcox, M.L., Peersman, W., Daou, p., Diakite, C., Bajunirwe, F., Mubangizi, V., Mah- moud, E.H., Moosa, S., Phaladze, N., \& Nkomazana, O. (2015) "Human resource for primary health care sub-Saharan Africa: progress or stagnation?" Human Resource Health 13:76. https://doi.org /10.1186/s12960-015-0073-8 PMid:26358250 PM-

\section{Cid:PMC4566492}

29). Williamson, M.I., Wilson, R., Mckechnie, R., \& Ross, J. (2012) "Does the positive influence of an undergraduate rural placement persist into postgraduate years?" The International Electrical Journal of Rural and Remote Health Research, Education, Practice and policy 12:2011. (Online) 2012

30). Yoo, E. Jung., Hwang, E. Seo., Lee, \& E.Ji. (2018) "The development of a community based medical education program in Korea" Korean J Med Educ. 30(4). https://doi.org/10.3946/kjme.2018.105 PMid:30522259 PMCid:PMC6288620 